\title{
BREXIT RESULTS: MACROECONOMIC RISKS
}

\author{
E. Goryunov, A. Kiyutsevskaya, P. Trunin
}

The United Kingdom's potential exit from the EU poses a number of macroeconomic risks. Considering the overall growth of uncertainty, the recession in the UK cannot be ruled out. The decline in capital inflows to the UK economy can be predicted, which could pose a threat to the stability of the balance of payments and the exchange rate of the British Pound. Obviously, the exchange of goods and services between the UK and the EU will suffer, as well as labour mobility and the British labour market. According to various estimates, Britain can lose up to 5\% of GDP as a result of capital outflows and shrinking international trade.

After the UK's exit from the EU, the country will cease to be in the common economic space with other European countries, so a need arises for the conclusion of numerous bilateral international agreements regulating areas such as migration and associated labour market, financial transactions between British and continental counterparts, international trade, taxation. Since neither the UK government nor Brexit supporters themselves have a clear, elaborated road map for exiting the EU, the fact that Britain decided to leave the European community creates considerable uncertainty ${ }^{2}$.

The sharp increase in macroeconomic and political risks led to a surge in volatility in financial markets. Economic agents' first reaction to the referendum results was panic. Oscillation amplitude of the FTSE stock index reached the historical maximum of 549.8 points: its quotes ranged from 6338.6 to 5738 points on the day the referendum results were announced. The pound sterling oscillation amplitude reached 0.179 on 24 June, whereas on average it did not exceed 0,019 US dollars in June and 0.013 US dollars in May (Fig. 1). In relation to the US dollar, the exchange rate of the pound sterling fell that day by more than $8 \%$.

In response to Brexit, Fitch and Standard \& Poor's rating agencies lowered the UK rating and forecast its further reduction. Fitch analysts also expect that the growth of risk premium and falling financial markets will lead to a reduction in aggregate demand and slowdown of economic growth in Britain from $2 \%$ to $0.9 \%$. So far, it's difficult to say whether the slowdown of economic growth will really be so significant, but the negative effect on stock markets is already obvious, and the possibility of recession can not be ruled out, taking into account the growth of the overall uncertainty.

In the situation of volatility spike and growing likelihood of slowing economic growth, the Bank of England decided to extend the standing facilities, i.e. the volume of daily operations providing overnight loans to banks at the rate of $0.75 \%$ per annum, up to 250 billion pounds, which is only one-third less than the quantitative easing program (375 billion pounds) introduced

1 This paper was originally published in Online Monitoring of Russia's Economic Outlook No.11(29).

2 See Avery, G. et.al. (2016). Britain's Future in Europe: The known Plan A to remain or the unknown Plan B to leave. CEPS Paperback $2^{\text {nd }}$ Ed., March 2016. 


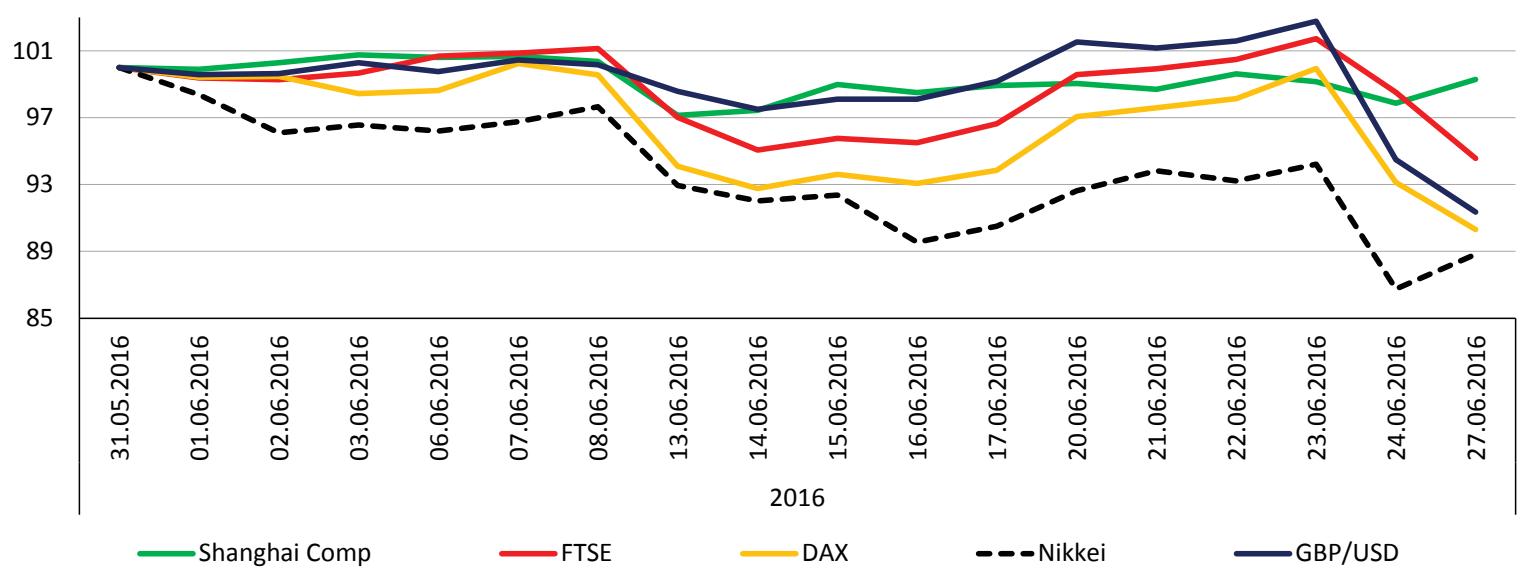

Source: RosBusinessConsulting, www.rbc.ru, authors' own calculations.

Fig. 1. Quotes of select stock indices and the pound sterling exchange rate $(31.05 .2016=100 \%)$

after the 2008-2009 crisis. At the same time, the regulator estimated that the capitalization of England's banking system is currently ten times higher than its pre-crisis level, which, according to the results of stress tests carried out by the regulator, ensures its sustainability in the case of the stress scenario ${ }^{1}$.

ECB also announced its readiness to support the banking system of the euro area by providing additional volumes of liquidity both in national and in foreign currency. The unanimity of the monetary authorities in this situation suggests that there are systemic macroeconomic risks not only for the UK but also for the euro area.

The United Kingdom's exit from the EU is not likely to significantly influence its budget policy. From a formal point of view, the UK will be freed from the commitment to observe budgetary discipline enshrined in the Maastricht Treaty, according to which the budget deficit should not exceed 3\% of GDP and public debt $-60 \%$ of GDP. In practice, however, these requirements were constantly violated. The state of public finances in the UK is not exactly satisfactory, and it will deteriorate in case of recession. Nevertheless, it is far from critical and corresponds to the EU average level.

The UK's exit from the EU is likely to negatively influence the country's banking sector, which has played a special role as a bridge between American financial institutions and the European economy. Previously, Asian and American banks sought to work with Europe primarily through London, but now its appeal might significantly decrease in favour of Frankfurt and Paris. Goldman Sachs and HSBC announced their plans to shift the focus of their business interests towards continental Europe in response to the the British electorate's decision. As a result, capital inflows into the UK economy will decrease, which could pose a threat to the stability of the balance of payments and the pound sterling exchange rate, given the significant negative current account: $-4.7 \%$ of GDP as of year-end 2015.

Industries related to international trade will also be affected, since Britain can lose free access to European markets. Continental European countries are the UK's main partners, and the emergence of additional barriers will

1 http://www.bankofengland.co.uk/publications/Documents/news/2016/056.pdf 
reduce the exchange of goods and services, while redirecting export and import flows will take considerable time.

An important consequence of the UK's exit from the EU may be restrictions on labour mobility, which would create obstacles for EU citizens' employment in the UK, reducing the flexibility of the UK labour market and leading to an increase in labour costs in the country.

It is difficult to reason about other possible long-term macro-economic consequences of the UK's exit from the EU because the conditions under which the exit will occur are unclear. One cannot rule out that political delaying of the exit process and changes in public sentiments will lead to Britain eventually remaining in the European Union. According to different estimates, as a result of capital outflows and shrinkage of the international trade, Britain can lose up to $5 \%$ of GDP ${ }^{1}$. The most pessimistic estimates suggest the loss of up to $8 \%$ of GDP2. So, the overall effect of the exit from the EU is most likely to be negative, and the factor determining its scale will be the terms on which British manufacturers and financial institutions will be able to access the European market.

1 See: OECD (2016), "The consequences of Brexit: a taxing decision", OECD Economic Policy Paper No.16.; PwC (2016), "Leaving the EU: Implications for the UK economy"; Open Europe (2015), "The consequences, challenges and opportunities facing Britain outside EU"; Ottaviano, Gianmarco, João Paulo Pessoa, Thomas Sampson, and John Van Reenen (2014), "The costs and benefits of leaving the EU".

2 See: Dhingra, Swati, Gianmarco Ottaviano, John Van Reenen and Jonathan Wadsworth (2016), "Brexit and the impact of immigration on the UK", CEP Brexit Analysis paper CEPBREXIT05; Bertelsmann Stiftung (2015), "Costs and benefits of a United Kingdom exit from the European Union"; HM Government (2016c), "HM Treasury analysis: the long-term economic impact of EU membership and the alternatives". 